\title{
INFÂNCIA E POLÍTICA
}

\author{
JENS QVORTRUP \\ Professor do Departamento de Sociologia e Ciências Políticas \\ da Universidade Norueguesa de Ciência e Tecnologia - Trondheim \\ jens.qvortrup@svt.ntnu.no \\ Tradução: Fátima Murad
}

\section{RESUMO}

As atitudes da nossa cultura em relação às crianças são ambíguas, o que se observa também na relação entre crianças e política. O modo protetor a que vêm sendo submetidas as crianças nos últimos dois séculos acaba por afastá-las dos adultos - e dos assuntos sérios da economia e da política. Como resolver esse dilema, que tem como consequência dificultar um discurso sobre crianças e política? Este artigo faz algumas reflexões sobre o tema e sugere que, em princípio, quando se trata de política, pode-se falar de: crianças como sujeitos; crianças/ infância como objeto não visado (em termos do impacto de forças estruturais); crianças/infância como objetos visados (iniciativas políticas voltadas às crianças) e, finalmente, como objetos instrumentalizados. A grande questão que se coloca em cada caso é saber em que medida as crianças são beneficiadas e se isso não ocorre como um efeito colateral dos ganhos para os adultos/sociedade adulta. Será que haveria investimentos públicos em crianças nas dimensões que alcançam hoje se não houvesse expectativas de um retorno lucrativo?

CRIANÇAS - INFÂNCIA - POLÍTICAS PÚBLICAS

\begin{abstract}
CHILDHOOD AND POLITICS. Our culture's attitudes towards children are ambiguous - as found also in the relationship between children and politics. The protective mood that has befallen children over the last two centuries entails their separations from adults - and from the serious business of economics and politics. How do we deal with the dilemma, which as a consequence makes it difficult to have a discourse about children and politics? This article nevertheless makes some reflections over the theme and suggests that one can, as far as politics is concerned, in principle talk about (a) children as subjects, (b) children/childhood as a non-targeted object (i.e. in terms of structural forces' impact), (c) children/childhood as targeted objects (political initiatives having children in mind), and finally as (d) instrumentalised objects. The thorny question raised in each case is to which extent children are beneficiaries or if that is the case
\end{abstract}

Este artigo é uma adaptação de minha palestra na conferência Educação para a cidadania na sociedade: um desafio para os países nórdicos, realizada em outubro de 2007, na Escola de Educação de Professores da Universidade de Malmö, na Suécia. A preparação original para uma apresentação oral ainda é bastante perceptível, pelo que me desculpo. 
primarily as a side effect of gains to adults/adult society. Would public investments in children have been made to the current extent, if expectations of a surplus return were not an option? CHILDREN - CHILDHOOD - PUBLIC POLICIES

O poeta e cantor sueco Beppe Wolgers é merecidamente famoso por sua linda canção Det gåtfulla folket [O povo misterioso]. Ela é cheia de magia, metamorfoses e outros encantos enigmáticos estranhos aos adultos. Em minha tradução, cada um dos três versos começa com: "Crianças são um povo e vivem em um país estrangeiro" e termina assim: "Todos são crianças e pertencem ao povo misterioso".

Não se pode duvidar nem por um instante que a canção de Wolgers seja uma declaração de amor às crianças, e ninguém estaria autorizado a submeter a poesia a uma análise dissecante sob pena de pôr em risco justamente essa impressão e o propósito do poeta. Porém, para um pesquisador da infância, é impossível não associar a leitura dessa letra a um interessante triplo retrato das crianças, no qual cada imagem revelaria um dos discursos atuais sobre crianças: como sentimentalizadas, como irracionais e como seres separados do mundo adulto.

Às vezes, os três retratos convergem, como ocorre de fato na canção de Beppe Wolgers. Outras vezes, poderíamos dizer que emitem mensagens divergentes. Em qualquer caso, não é nenhum exagero afirmar que a atitude de nossa cultura quanto às crianças é ambígua. Essa ambiguidade está claramente presente também no tema deste artigo sobre a relação entre infância e política.

Não é difícil encontrar representantes dos pontos de vista de Wolgers entre pesquisadores que trabalham com crianças. James Garbarino, um reconhecido psicólogo norte-americano, pode servir de exemplo. Anos atrás, ele afirmou que, em nossa era moderna, ser criança é "estar protegido das demandas diretas de forças econômicas, políticas e sexuais... infância é um tempo para maximizar o particularismo e minimizar o universalismo, uma definição que deveria ser levada em conta igualmente por educadores, políticos e pais" (1986, p. I20).

Esse ponto de vista reforça a observação feita pela socióloga argentino-americana Viviana Zelizer (1985), cujo livro notável Pricing the priceless child [Dar um preço à criança sem preço] revela de forma muito convincente a profunda mudança nas atitudes de nossa cultura quanto às crianças - mudança na direção de uma atitude muito mais emocional, captada por Zelizer nas 
noções de sentimentalização e sacralização. Essa direção, como se vê, está em total harmonia com o modo protetor de Garbarino. Ao mesmo tempo e isso está presente também na definição de Garbarino -, foi a mudança de posição da infância ao longo da história que criou uma distância entre grupos etários. A mesma observação foi feita por outros estudiosos que têm histórias para contar um pouco diferentes das de Garbarino. Ruth Benedict, conhecida antropóloga norte-americana, colocou a questão da seguinte maneira: "De uma perspectiva comparativa, nossa cultura atinge níveis extremos ao enfatizar os contrastes entre a criança e o adulto [...] são todos dogmas de nossa cultura, dogmas que [...] nem sempre são aceitos por outras culturas" (| 938, p. |6 |).

famoso historiador francês Philippe Ariès aparentemente compartiIhava o ponto de vista de Benedict, embora o aplicasse ao contexto histórico, enquanto Benedict comparou culturas contemporâneas no início do século 20. Ariès observou assim "o início de um longo processo de segregação [...] que prossegue até hoje e que é chamado escolarização". E, nessa linha de raciocínio, ele fala sobre "esse isolamento de crianças e sua entrega à racionalidade" (1982, p.7).

Há, no entanto, uma grande diferença entre Garbarino (e Wolgers, nessa questão), de um lado, e Benedict e Ariès, de outro. Enquanto Garbarino defende a separação entre o mundo das crianças e o dos adultos como forma de proteger as crianças de um mundo perigoso - e portanto considera o pequeno núcleo familiar como o ideal para as crianças -, Benedict e Ariès, ao contrário, são céticos quanto ao estado de coisas atual. Eles lamentam o que acreditam que esteja ocorrendo, ou seja, que as crianças tenham perdido sua posição como participantes da sociedade.

Esse debate entre várias posições prossegue entre nós: deveríamos fazer de tudo para proteger as crianças ao preço de deixá-las fora da "sociedade" ou deveríamos reconhecê-las como pessoas, participantes, cidadãs com o risco de expô-las às forças econômicas, políticas e sexuais - vistas como um perigo por Garbarino?

Acredito que tanto Garbarino quanto Ariès/Benedict têm bons argumentos. De fato, ninguém está disposto a sacrificar a necessária proteção das crianças expondo-as a todos os riscos de uma sociedade moderna; porém, ninguém concordaria em privar as crianças de se experimentarem como pes- 
soas que contribuem para a sociedade. A questão agora é saber se essas várias posições interferem na nossa discussão atual sobre infância e política.

\section{CRIANÇAS COMO SUJEITOS NA POLÍTICA}

Hoje há muitas considerações abalizadas e muito debate público sobre direitos das crianças e crianças como cidadãs. Essas discussões têm muito a dizer em termos gerais e também em termos mais particulares sobre o status das crianças na sociedade e sobre o que crianças podem esperar legitimamente como membros da sociedade. A Convenção da Organização das Nações Unidas - ONU sobre Direitos da Criança contém vários artigos que se costuma dividir coloquialmente em três grupos (os chamados três Ps): um que trata da proteção, outro da provisão e um terceiro dos direitos de participação.

No que se refere ao status de sujeito das crianças, seus direitos de participação são bem mais relevantes. A participação é entendida aqui principalmente em termos de direitos que têm muita semelhança com os direitos humanos e civis na Declaração dos Direitos Humanos. Assim, o art. 12, da Convenção sobre os Direitos da Criança, fala em assegurar à criança que é capaz de formar suas próprias opiniões o direito de expressá-las livremente em "assuntos que afetam a criança"; o art. 13 garante à criança liberdade de expressão; o art. I4, liberdade de pensamento, consciência ou religião; o art. I 5, liberdade de associação e reunião pacífica; e o art. 16, direito à privacidade.

Todos esses artigos valorizam a subjetividade da criança - mas há muitas limitações. A mais significativa, a meu ver, encontra-se no art. 12, que estabelece que somente em assuntos que afetam a criança ela teria direito de opinar livremente. Essa é uma limitação grave, mas provavelmente sintomática da criança como sujeito político em nossas sociedades.

Nas discussões sobre direitos das crianças, como também sobre cidadania de maneira geral, pesquisadores e políticos nos deixam em uma espécie de limbo e demonstram que não se pensou realmente nas crianças. Assim, Marshall ( 1950), cientista político britânico que escreveu um livro muito sugestivo sobre cidadania depois da Segunda Guerra Mundial, não encontrou um lugar para as crianças; o filósofo do direito americano John Rawls ( 1971) mostrou a mesma dificuldade; e o sociólogo alemão-britânico Ralf Dahrendorf ( 1996) fala explicitamente das crianças como "um problema embaraçoso" - em outras 
palavras, um problema irritante e enfadonho que atrapalha discussões sérias entre pessoas adultas sobre pessoas maduras.

Nessa linha de raciocínio é notável, e altamente relevante para o meu tema Infância e Política, que a disciplina acadêmica que mostrou menos interesse pelas novas vertentes dos estudos da infância tenha sido a Ciência Política. Se ela manifesta alguma curiosidade pelas crianças, o interesse se concentra exclusivamente na socialização política, ou seja, em como preparar melhor as crianças para se tornarem pessoas responsáveis politicamente, o que supostamente exigiria um certo nível de atividade política e, em todo caso, suficiente para satisfazer a expectativa mínima de um sistema democrático: votar.

Esta expressão de cidadania - a demonstração da real soberania, a pessoa como eleitor - não é mencionada entre as cláusulas da Convenção Internacional sobre Direitos da Criança. Uma das razões possíveis é que a expressão transcenderia aquilo que se diz sobre "assuntos próprios da criança" - o que aparentemente é entendido em um sentido bastante estreito. A ideia de que estruturas maiores podem influenciar a criança de maneira muito direta parece estar além das preocupações da Convenção. Outra razão está relacionada explicitamente ao fato de que a criança não teria competência para votar. A criança seria politicamente imatura.

Não quero discutir o argumento em si. Isso pode até ser verdade, mas, nesse caso, é preciso fazer três perguntas: se a competência é o principal critério para votar, é seguro então que todas as pessoas politicamente incompetentes são impedidas de votar, independente da idade? A sociedade seria prejudicada se crianças fossem eleitores? A criança (ou as crianças) sofreria(m) algum dano, injustiça ou iniquidade por não terem acesso às urnas?

Em resposta à primeira pergunta, poderíamos mencionar Hilary Rodham - mais conhecida hoje como Hilary Clinton - que, muitos anos atrás, foi advogada de uma criança, sugeriu, de forma provocativa, "reverter a presunção de incompetência e reconhecer, ao invés disso, que todos os indivíduos são competentes até que se prove o contrário" (apud Lasch, 1992, p.75). $\bigcirc$ que ela está dizendo então é que não se pode tomar como certo que pessoas abaixo de uma determinada idade arbitrária sejam politicamente incompetentes. Não é difícil encontrar pessoas abaixo dessa idade que têm essa competência, como é bem possível encontrar muitas outras acima da idade que não são politicamente competentes. Sendo assim, há um problema 
de equidade, que não é resolvido, mas apenas mencionado com referência ao expediente, embora reconhecendo que todas as pessoas com menos de 18 anos de idade são incompetentes. Ninguém tem dúvida de que seria totalmente impraticável testar a competência não apenas das crianças, mas também de cada membro da sociedade. Não acho que seja um problema simples, e muito já se pensou e escreveu sobre ele, mas paro por aqui.

Com relação à segunda pergunta, seria provavelmente muito difícil demonstrar que a sociedade como tal estaria correndo um risco se as crianças pudessem votar. Minha suposição é que a distribuição dos votos não se desviaria muito de um resultado habitual. Não vou ignorar a alegação de que isso seria extremamente perturbador para qualquer saber convencional, mas pode ser também uma maneira de enfatizar a responsabilidade pelos valores comuns.

Quanto à terceira pergunta, é muito mais importante perguntar se as crianças - dada sua condição de não votantes - têm uma representação política adequada. É preciso ter em mente que estamos nos referindo, na verdade, a cerca de 20 a 25 por cento da população (com menos de 18 anos) nos países europeus. Em outras partes do mundo, é maior ainda a porcentagem daqueles que não podem afirmar que são diretamente representados na política. É claro que se poderia argumentar, como é usual, que eles têm bons representantes em seus pais.

Examinemos esse argumento. A principal suposição, quando se trata do comportamento eleitoral, é que as pessoas votam de acordo com o que presumem ser do seu próprio interesse. Assim, os adultos sem filhos [crianças]' entre eles os idosos, não teriam em mente os interesses das crianças [filhos] ao preencher a cédula. Não se pode nem mesmo garantir que os pais pensem nos interesses de crianças [filhos] ao votar, mas, quanto a este argumento, acredito que eles realmente o façam. Nesse caso, então, as crianças serão representadas apenas por pais com os quais convivem diariamente. Sabemos, por exemplo, que, nos países escandinavos, apenas um quarto das famílias têm filhos; sabemos também que há um grande percentual de pessoas com mais de 60 anos de idade e que essa faixa da população tende a crescer. Calcula-se que em um

I. Nos dois próximos parágrafos colocamos entre colchetes os termos "crianças(s)" ou "filhos(s)" ao lado da tradução de child ou children para alertar ao leitor as duas possibilidades de tradução (N. da E.) 
futuro relativamente próximo, mais da metade do eleitorado terá mais de 50 anos, e assim por diante. Em certo sentido, há muita especulação nisso, mas o desenvolvimento demográfico não trabalha a favor dos interesses das crianças.

Deixando de lado a possibilidade de permitir que as crianças votem, haveria ainda a alternativa de beneficiar os pais com votos adicionais - um voto para cada filho [criança]. Um casal com dois filhos [criança] teria, no caso, direito a quatro votos nas eleições (se esse direito deveria ser concedido à mãe ou ao pai do mesmo sexo ou do sexo oposto ao do filho, essa é uma outra questão). A proposta pode criar problemas constitucionais que, no caso, deixo a cargo dos cientistas políticos, advogados e políticos - sem desmerecer os efeitos negativos que podem decorrer disso.

A questão é que, em qualquer caso, as crianças possivelmente não são bem representadas hoje e, dada a tendência demográfica, não há perspectivas de reverter esse desequilíbrio. Podemos então concluir nossas considerações sobre as crianças como sujeitos políticos afirmando que nosso sistema não abre canais para que as crianças ajam como tal, e é improvável que eles venham a ser criados por uma população em crescente processo de envelhecimento.

\section{CRIANÇAS/INFÂNCIA COMO UM OBJETO NÃO FOCALIZADO DE POLÍTICA}

É preciso estar ciente de que muitas políticas acarretam consequências inesperadas, ou seja, consequências que não eram nem previstas nem necessariamente desejadas. Em outras palavras, devemos fazer uma distinção entre políticas que pretendem ter impacto nas crianças ou na infância e políticas que não têm esse objetivo, mas que podem ter grandes consequências para elas para o bem ou para o mal.

Pode-se argumentar que, na medida em que essas políticas não são direcionadas à infância, não há por que discuti-las. Mas esse argumento é indefensável - eu diria, inclusive, que muito do que se passa com a infância no sentido de sua formação e transformação, e muito do que influencia as crianças no seu dia a dia é, na verdade, instigado, inventado, ou simplesmente ocorre sem que houvesse a menor preocupação com as crianças ou a infância. Se isso é verdade, a única maneira de evitar o negativo ou de promover o positivo dessas políticas 
quando elas afetam as crianças e a infância é fazer um diagnóstico. Por que existem tantas crianças pobres? $\bigcirc$ que explica que essas crianças, mais do que outros grupos, venham de famílias numerosas? Isto não se deve, evidentemente, a uma conspiração contra as crianças. Mas simplesmente aconteceu dessa maneira por desatenção, indiferença estrutural ou outra coisa.

Não é difícil encontrar exemplos desse tipo de políticas - ou mesmo de eventos sociopolíticos ou político-econômicos - que poderiam ser definidas em termos de uma influência não intencional na esfera da infância ou da vida das crianças. Pode ser qualquer evento ou desenvolvimento social, político ou econômico de uma certa magnitude. Vou citar um exemplo familiar para nós.

Como todos sabemos, durante longos períodos, pelo menos na segunda metade do século $X X$, houve um aumento drástico da participação das muIheres no mercado de trabalho. Esse aumento não foi direcionado a atender as necessidades das crianças - muito pelo contrário, diriam muitos, embora não se tenha tanta certeza disso. De todo modo, foi um desenvolvimento que teve um enorme impacto na infância e na vida das crianças. Em muitos países, foi acompanhado da criação de jardins de infância, creches, centros de atendimento para depois do horário escolar etc., onde as crianças são obrigadas a passar grande parte de sua infância. Esse é um exemplo de política que visa deliberadamente a infância, embora, em um primeiro momento, a entrada das mulheres no mercado de trabalho não incluísse uma preocupação com as crianças ou a infância; ela se tornou necessária em um segundo momento.

Se olharmos um pouco para trás na história - por exemplo, para o início do "século da criança", como foi chamado por Ellen Key -, observaremos uma série de eventos que foram característicos da transição para a sociedade industrial moderna. Observamos fenômenos como industrialização, mecanização, urbanização, secularização, individualização e democratização. Esses títulos, como tais, representam transformações na sociedade em geral, e constituíram respostas às demandas para que o crescimento econômico prosseguisse. Se perguntássemos onde ficam as crianças nisso, a resposta seria, em primeiro lugar, que elas não eram levadas em conta; não eram o alvo como tal. Mesmo assim, se mantivermos o olhar nas crianças, logo descobriremos que elas foram profundamente atingidas pelas transformações que não as visavam. Isso pode ser constatado em outra lista de eventos simultâneos: abolição do trabalho infantil, movimento de defesa da criança, escolarização em massa, queda da 
fertilidade, sentimentalização e novo interesse científico - para mencionar as mais importantes e evidentes entre as novas variáveis.

A ideia aqui é que a transformação da infância não foi, na verdade, o resultado de uma política deliberada que visasse a esse propósito explícito. Contudo, não se pode subestimar o alcance e o significado do impacto na infância de parâmetros macroeconômicos, macropolíticos e macrossociais. A infância nunca mais foi a mesma depois dessa passagem pelo período de industrialização.

A primeira lição que se tira daí é que a infância é involuntariamente gostemos ou não - parte da sociedade e da política social. Qualquer esforço para excluí-la ou mantê-la à margem é ilusório. Assim, a segunda lição é que se deve estar permanentemente atento às consequências para a infância de todos os tipos de política - inclusive as que não visam à infância.

Em alguns países, foram criados ministérios da infância. É lá, supõe-se, que são elaboradas a política e as políticas para a infância. Nenhuma dúvida quanto a isso. Contudo, é preciso considerar que as decisões tomadas nos ministérios das finanças, da habitação, dos transportes, do planejamento urbano e em outros ministérios mais amplos têm um impacto muito maior na infância do que as de um órgão exclusivo para as crianças.

\section{CRIANÇAS/INFÂNCIA COMO UM OBJETO FOCALIZADO PELA(S) POLÍTICA(S)}

Há, obviamente, iniciativas políticas que visam diretamente às crianças e à infância. Se examinarmos a legislação de qualquer país ou a Convenção Internacional da ONU sobre os Direitos da Criança, vamos encontrar muitos preceitos legais dirigidos efetivamente às crianças, seja no sentido de protegê-las, de provê-las ou de possibilitar sua participação - os três Ps que já mencionamos. Poderíamos imaginar também, a esse respeito, que tais iniciativas visariam proteger a sociedade adulta. É a impressão que se tem, pelo menos parcialmente, quando em alguns países, como Estados Unidos e Grã-Bretanha, são aprovados projetos de lei referentes ao toque de recolher.

Mas, em geral, não é fácil determinar se certas iniciativas ou projetos de lei visam às crianças, à família, aos pais, às mães ou a qualquer outra pessoa. Um jardim de infância, por exemplo, destina-se às crianças ou aos pais - ou ao 
Estado e às empresas? Enfim, pode ser que jardins de infância beneficiem várias partes, ainda que provavelmente algumas delas se beneficiem mais do que outras.

No quadro I, faço duas distinções: uma entre infância e crianças (ou a criança) e outra entre política e políticas. A noção de infância não considera a criança individual, e sim arranjos legais, espaciais, temporais e institucionais voltados às crianças em uma determinada sociedade. Podemos falar de infância como um fenômeno social, como uma construção social ou algo parecido. Sua forma ou arquitetura depende de parâmetros como economia, tecnologia, cultura, atitudes adultas etc., e da interação entre eles. Visto que esses parâmetros mudam e assumem continuamente novas configurações, a infância nunca é a mesma - mesmo que seja da mesma natureza. Se compararmos a infância na Suécia em 2007 e a infância na Suécia em 1907, perceberemos que continuamos falando de infância, mas também que ela mudou. Ela mudou porque a sociedade e sua indústria mudaram - mas também porque o Estado pode ter intervido para corrigir mudanças não esperadas.

Se utilizarmos a noção de "casa," é óbvio que as crianças, literalmente falando, vivem no apartamento ou casa dos pais. Mas também se pode dizer metaforicamente que as crianças vivem na casa da infância - que aparece como resultado de intervenções esperadas e consequências não esperadas. Elas vivem ali somente por um certo período; e então se mudam da casa da infância, primeiro para a casa da adolescência e depois para a casa da idade adulta que, do mesmo modo, constituem instituições culturais com certa permanência.

A noção de política é uma resposta a questões de orientação, do caminho a seguir, e isso inclui questões ideológicas. As políticas, por sua vez, são respostas a problemas práticos e resultarão em decisões pontuais.

QUADRO I

INICIATIVAS POLÍTICAS EM RELAÇÃO ÀS CRIANÇAS/INFÂNCIA*

\begin{tabular}{|l|c|c|}
\hline & Infância & Criança(s) \\
\hline Política & 1 & 2 \\
\hline Políticas & 3 & 4 \\
\hline
\end{tabular}

No quadro I, politics foi traduzido por política e policies por políticas (N. da T.).

Quando falamos então de política da infância, como na casela I, temos em mente uma decisão política sobre o que nós, como sociedade, queremos 
com ou para a infância, isto é, decisões sobre a estrutura da infância, sobre o lugar da infância em uma sociedade dominada por adultos, sobre o direito da criança de votar, e principalmente sobre questões de larga escala ou macro que, de maneira geral, interferem no mundo das crianças. A maneira pela qual a infância é vista depende do período histórico ou da civilização; a política da infância se refere à maneira de desenhar estruturalmente a infância e de mudar conscientemente a sua arquitetura. Estamos interessados na situação e no desenvolvimento da infância como um segmento estrutural da sociedade.

Se, por outro lado, observamos a casela 2, política para crianças, temos em mente iniciativas nacionais de longo prazo voltadas ao desenvolvimento das crianças como grupo. A "política para crianças" englobará diversas coortes de crianças e, portanto, independente de crianças individuais.

A casela 3 - políticas para infância - pode focalizar aquilo que Bronfenbrenner (1979) chamou de ecologia da infância. Elas seriam implementadas tipicamente em nível municipal.

Finalmente, a casela 4 - políticas para a criança - incluiria tipicamente programas especiais para crianças individuais, por exemplo, crianças em risco.

$O$ equilíbrio entre as medidas mencionadas no quadro provavelmente será variável dependendo do regime político. Em sistemas muito orientados à família, as iniciativas parecem ser menos numerosas do que, por exemplo, nos Estados de bem-estar nórdicos.

\section{CRIANÇAS/INFÂNCIA COMO UM OBJETO INSTRUMENTALIZADO EM POLÍTICA}

As crianças sempre tiveram um papel específico - a saber, o de matéria-prima para a produção de uma população adulta. É por isso que sempre nos referimos a elas como nosso futuro ou como a próxima geração. Essa maneira de falar levanta inevitavelmente a suspeita de que a infância não é nosso alvo principal, mas apenas um instrumento para outras propostas. É uma resposta à pergunta que todos os adultos fazem a todas as crianças: o que você vai ser quando você crescer? Tipicamente, os adultos não estão interessados no que as crianças são enquanto crianças.

O papel das crianças como matéria-prima ou como recurso é historicamente, como mostrarei, a ideia mais persistente e mais dominante sobre as 
crianças, mas, apesar dessa persistência, os argumentos em favor dela podem mudar completamente. Assim, por exemplo, já foi senso comum outrora que as crianças deviam apanhar ou ser espancadas sob o argumento de que isso era necessário para o êxito na futura vida adulta. "Mimar demais estraga a criança" é apenas um dos muitos provérbios ou expressões a esse respeito. Hoje, no entanto, com mais conhecimento, descobrimos que não se deve punir fisicamente as crianças. $\bigcirc$ curioso é que nosso objetivo não mudou: queremos ainda produzir um adulto melhor. A nova versão tem a vantagem de estabelecer uma situação melhor para todos: as crianças devem ser felizes enquanto se desenvolvem para se tornarem adultos ideais. Uma pergunta crucial, nesse contexto, seria: como agiríamos em relação às crianças se os ventos mudassem outra vez e novas descobertas provassem que a perspectiva de êxito na idade adulta pendia inequivocamente em favor de espancá-las?

Na verdade, acho que não há nada de estranho nisso, visto que, na maioria dos países do mundo, crianças são espancadas e, inclusive, em algumas classes sociais nos países onde isso é proibido por lei - e portanto de conhecimento público - muitas pessoas preferem não correr o risco de deixar de punir fisicamente as crianças. Em outras palavras, na dúvida, essas pessoas optam por uma situação em que as crianças perdem e os adultos ganham, ou as crianças são instrumentos para a produção de um bom adulto (Quadro 2).

Poderíamos considerar ainda as iniciativas recentes com relação a estratégias de investimento social, tanto do novo Partido Trabalhista britânico como da União Europeia -, subscritas por figuras notáveis como Tony Blair, George Brown, Anthony Giddens e Gøsta Esping-Andersen. Argumentos a favor dessas estratégias são quase inteiramente enunciados em termos de desenvolvimento do capital humano e da qualidade de uma futura força de trabalho. Em termos gerais, sugere-se uma identidade entre interesses sociais e qualidade de vida adulta. Assim como a abolição da punição física de crianças, eles postulam uma situação favorável a todos, dando por suposto que todos temos os mesmos interesses. Mas, será que é isso mesmo? Será que o que é bom para o Estado e para a sociedade corporativa é bom também para as crianças? E será que sabemos o que é essa boa idade adulta que pretendemos produzir? As estratégias de investimento social visam ao cidadão trabalhador, mas podem visar também ao parceiro bom e cuidadoso e ao pai/mãe amoroso. Será que o que é neces- 
sário para produzir o trabalhador é o mesmo que é necessário para produzir o parceiro e o pai/mãe?

QUADRO 2

DAS OPÇÕES FAVORÁVEIS ÀS OPÇÕES DESFAVORÁVEIS SEGUNDO GRAUS E/OU TIPOS DE INVESTIMENTOS SOCIAIS (OU PUNIÇÃO FÍSICA DAS CRIANÇAS)

\begin{tabular}{|l|c|c|}
\hline & Infância/Crianças & Idade adulta/Sociedade \\
\hline Opção 1 & Ganha & Ganha \\
\hline Opção 2 & Perde & Ganha \\
\hline Opção 3 & Ganha & Perde \\
\hline Opção 4 & Perde & Perde \\
\hline
\end{tabular}

Em qualquer caso, os estrategistas de investimento postulam que as perspectivas voltadas para o futuro e produtivistas coincidem com o que eles acreditam ser uma vida boa para a criança. Mesmo que concordemos com isso, a questão crucial ainda permanece: e se essa conexão não for muito evidente? Em princípio, temos, como no caso da punição física, quatro opções ou situações (Quadro 2): ganha-ganha, perde-perde, ganha-perde e perde-ganha.

Ganha-ganha é a melhor e perde-perde a pior - o que é uma constatação óbvia. Se tivermos alguma influência, rejeitaremos o perde-perde, mas isso não nos garantirá um ganha-ganha. Podemos então ficar com um ganha-perde e um perde-ganha. Dá para imaginar o resultado ganha-perde, ou seja, um resultado em que as crianças ganham e os adultos perdem? Sim, em certas famílias, talvez, mas, a longo prazo, a sociedade adulta não permitirá que essa opção prevaleça. Sugiro então que, depois do ganha-ganha no ranking, venha o perde (para crianças)-ganha (para adultos). Essa sugestão se deve principalmente a que os adultos têm, de fato, direito e poder para escolher. Faz parte da lógica de todos os argumentos convencionais, defendidos, por exemplo, por Esping-Andersen (2002), que, na dúvida, a sociedade adulta ou os adultos fiquem com o melhor.

No momento, assistimos a novas discussões sobre escolarização e, em alguma medida, temos os mesmos debates sobre jardins de infância. A interpretação dos resultados atuais do Programa Internacional de Avaliação de Alunos - Pisa -, por exemplo, é que a disciplina ficou muito frouxa e que os professores tornaram-se muito amigáveis com os alunos. Essas são carac- 
terísticas supostamente do interesse dos alunos, pelo menos a curto prazo. Contudo, esses argumentos perdem a validade quando os resultados esperados pela sociedade adulta não são obtidos ou são questionados. Assim, assistimos a essas longas discussões europeias sobre encurtar a corda, sobre a reintrodução de testes, da disciplina etc. De maneira geral, Gordon Brown, em 200 I, como ministro da Fazenda, investiu nas crianças pensando no retorno:

A pobreza infantil é uma cicatriz na alma da Grã-Bretanha e é porque nossas crianças de cinco anos de idade são nossos futuros médicos, enfermeiros, professores, engenheiros e trabalhadores que, por razões não apenas de justiça social, mas também de eficiência econômica, deveríamos investir em... todo o potencial de todas as nossas crianças. (apud Jenson, 2006, p.39, grifos meus)

Em termos econômicos, a experiência mostra o que pode acontecer se o progresso econômico for interrompido por uma crise: em Estados de bem-estar tão reputados como a Suécia e a Finlândia no início dos anos 1990, as despesas públicas com crianças e programas relacionados à criança foram cortadas de forma desproporcional. Como já sabíamos, e se confirmou, as crianças não reivindicam recursos sociais, mesmo porque sua força e seu poder de negociação são irrelevantes.

Os dois exemplos mencionados demonstram uma certa unanimidade no que se refere às metas - de resto, quem se oporia à intenção de ter bons adultos? Ao mesmo tempo, percebemos que os meios para alcançar esse fim podem variar com o tempo e entre países e, mais ainda, entre classes ou grupos religiosos. No caso dos Estados Unidos, o filósofo Lakoff (2002) mostrou, por exemplo, que as atitudes do país em relação ao espancamento se dividem entre em um Sul religioso fundamentalista e um Norte mais liberal.

\section{CONCLUSÕES}

É óbvio que infância e política estão inerentemente ligadas. É igualmente óbvio que todos desejamos proteger as crianças dos piores efeitos da política e da economia. Contudo, manter as crianças fora da economia e da política é irrealista. Entre outras razões, isto é provado pelo fato de que as crianças são parte de um projeto que faz delas a matéria para a construção do futuro. 
Para sintetizar, eu diria que as crianças estão entre dois extremos: de um lado, uma "sentimentalização", que busca separar as crianças do mundo adulto e protegê-las contra ele, de outro lado, uma "indiferença estrutural" ou desatenção (Kaufmann, 2005, p. I 52- I 53), o que, na realidade, dá no mesmo. Desenvolvimentos políticos e econômicos acontecem às nossas costas e ocorrem sem a devida consideração às crianças e à infância - não necessariamente por má vontade, mas simplesmente porque costumamos ver as crianças como um fenômeno altamente privatizado.

Procurei demonstrar que mesmo que a política e as políticas, em alguma medida, estejam deliberadamente focalizando as crianças e a infância, talvez a influência mais marcante na vida das crianças venha das ações não focalizadas e instrumentalizadas direcionadas às crianças e à infância. Assim, se permanece importante focalizar as crianças diretamente, talvez devêssemos ficar mais atentos a todas as influências sobre as crianças que não planejamos e que desconhecemos.

A ideia de "crianças como sujeitos políticos" continua sendo no presente, como fora no passado, um conto de fadas.

\section{REFERÊNCIAS BIBLIOGRÁFICAS}

ARIÈS, P. Barndommens historie. København: NNF Arnold Busck, 1982.

BENEDICT, R. Continuities and discontinuities in cultural conditioning. Psychiatry, Arlington, v. I,n.2, p. 161-167, 1938.

BRONFENBRENNER, U. The Ecology of human development: experiments by nature and design. Cambridge: Harvard University, 1979.

DAHRENDORF, R. Citizenship and social class. In: BULMER, M; REES, A. (Ed.). Citizenship today: the contemporary relevance of T. H. Marshall. London: UCL, 1996. p.25-48.

ESPING-ANDERSEN, G. A Child-centred social investment strategy. In: ESPING-ANDERSEN et al. (Ed.). Why we need a new welfare state. New York: Oxford University, 2002. p.26-67.

GARBARINO, J. Can american families afford the luxury of childhood? Child Welfare, Arlington, v.65, n.2, p. $119-128,1986$.

JENSON, J. The Lego TM paradigm and new social risks: consequences for children. In: LEWIS, J. (Ed.). Children, changing families and welfare states. Cheltenham: Edward Elgar, 2006. p.27-50. 
KAUFMANN, F. X. Schrumpfende Geselsschaft: Vom Bevölkerungsruckgang und seine Folgen. Suhrkamp: Frankfurt, 2005.

LAKOFF, G. Moral politics: how liberals and conservatives think. Chicago: The University of Chicago, 2002.

LASCH, C. Hilary Clinton, child saver. Harpers Magazine, New York, p.74-82, Oct. 1992. Disponível em: <http://www.harper.org.archive//992/l0/000l >. Acesso em: set. 2010.

MARSHALL, T. H. Citizenship and social class and other essays. Cambridge: Cambridge University, 1950.

RAWLS, J. A theory of justice. Cambridge: Belknap, 197I.

ZELIZER, V. A. Pricing the priceless child: the changing social value of children. Basic Books: New York, 1985.

Recebido em: setembro 2010

Aprovado para publicação em: setembro 2010 